\title{
A Gentle Push to Reduce the Frequency of Smartphone Use in Corporate Meetings
}

\author{
Vaccaro $\mathbf{M}^{1,4}$, Venanzi $\mathbf{P}^{2}$, Bisagni $\mathbf{M}^{3}$, Pozzi $\mathrm{F}^{1,4}$ and Moderato \\ P1,3,4 \\ 1IULM, International University of Languages and Media, Italy \\ 2Venanzieffe SRL, Italy \\ ${ }^{3}$ Ascco, Academy of Behavioral and Cognitive Sciences, Italy \\ ${ }^{4}$ IESCUM, European Institute for the Study of Human Behavior, Italy
}

*Corresponding author: Marianna Vaccaro, IESCUM, European Institute for the Study of Human Behavior, P.le Ravenet n. 543100 - Parma, Italy, Tel: (+39) 3489132738; Email: marianna.vaccaro@yahoo.it

\begin{abstract}
In order to address the problem of the high frequency of smartphone usage during company meetings, a nudge intervention was developed in a Lombardy company to reduce its usage The use of two nudge techniques, simplification and social norms, has allowed the participants to push gently, without punishment or economic incentives, to reduce the usage of their device during meetings between employees and the company manager. The data showed that, under experimental conditions, the frequency of use of the devices was reduced compared to the control rate, which suggests the effectiveness of the intervention.
\end{abstract}

Keywords: Smartphone; Corporation; Nudge; Simplification; Social Norms; Use

\section{Introduction}

The 21st century has seen the use of technology becoming an inevitable part of everyday life. Being constantly connected, during the day, at any time, thanks to the presence and use of smartphones, creates frequent interruptions and distractions and leads to a decrease in the ability to maintain active attention and to reflect on things [1,2]. Multitasking, or being able to perform multiple actions at the same time, is one of the abilities developed by man following the spread of the smartphone in the various contexts of everyday life (for example, talking or texting while you are driving, walking, shopping or watching television), and the emerging trend is to believe that this tool can facilitate contact with people, coordinate daily activities and lead to an increase in productivity [3]. Multitasking through the smartphone creates the illusion of saving time but on the contrary, recent research has shown that the consequences of the shift of attention between different tasks have negative outcomes, as they are a cost in terms of time, energy, commitment and effectiveness during information processing. The conviction of being able to perform more activities simultaneously without additional cognitive costs seems to have no foundation [4,5], as in most cases dividing the attention between tasks makes the process slower and more complex, and leads to a decrease of the quality of the processing and the amount of information learned [6-10].

The smartphone is often present in multiple contexts including company meetings. The studies in the literature 


\section{Ergonomics International Journal}

highlight the presence of policies aimed at prohibiting, even for a short period of time, the use of the device during meetings as it is considered a disrespectful behavior towards the interlocutor, done with high frequency, with consequent lack of concentration and listening [11].

Research conducted in the United States demonstrates how the daily checking of the mobile device has become a routine behavior: the action of checking finds in the information acquired, in the responses of text messages and calls a reinforcement that involves an increase in the frequency of the behavior. A person would tend to consult their device on average about every 16 seconds, equal to 2,000 times a day, against the 150 times detected only four years ago [12].

The use of instant messaging, social networks and online games leads literature to talk about smartphone addiction today $[13,14]$. The research conducted in a Lombardy company, Venanzi Effe, which has been longinvolved in the disposal of hazardous and non-hazardous waste, required the intervention of the Nudge Italy Team to reduce the frequency of use of the smartphone during work meetings.

The term Nudge, translated into Italian as "gentle push" describes how a piece of architecture of choice can change people's behavior in a predictable way, without using incentives or punishment [15]. Sustainability and low cost are unique characteristics of the approach. In the literature there are numerous existing nudging interventions that demonstrate how providing clear and simple information on the behavior that we want to be issued, makes some behaviors more salient [16-21]. The Nudge is a form of behavioral modification widespread in Italy thanks to the publication of the book "The gentle push" by Sunstain and Thaler [15], which has captured the attention of researchers over time and is spreading like wildfire, even if slowly, in different regions of the country.

\section{Materials and Methods}

The research conducted in a Lombardy company, VenanziEffe, which has been long involved in the disposal of hazardous and non-hazardous waste, required the intervention of the Nudge Italy Team to reduce the frequency of use of the smartphone during work meetings. The realization of the intervention was possible with the consent of the Manager. The behavioral survey lasted two weeks: one for the control phase and one for the experimental phase, in March and April 2019.
Specifically, the observations were carried out in the morning from 9:30 to 11:30. All participants $(n=15)$ were employees of the company and external collaborators.

\section{Materials}

The experimenters observed and assessed the behavior of the people sitting at the meeting table, with the following tools:

- Observation grids created ad hoc for each phase of the research. Both on the control cards and on the experimental cards there were boxes to record the number of people sitting at the table, and the number of those interacting with the smartphone (Figure 1).

- List of target behaviors (Table 1).

- Audio file which said the number of the participant to be observed every 5 .

- Electronic device to play the audio file (smartphone of one of the two observers).

- Earphones (two pairs, one for each observer).

- Jack splitter to connect the two pairs of earphones to the same electronic device that reproduced the audio file created ad hoc for observation.

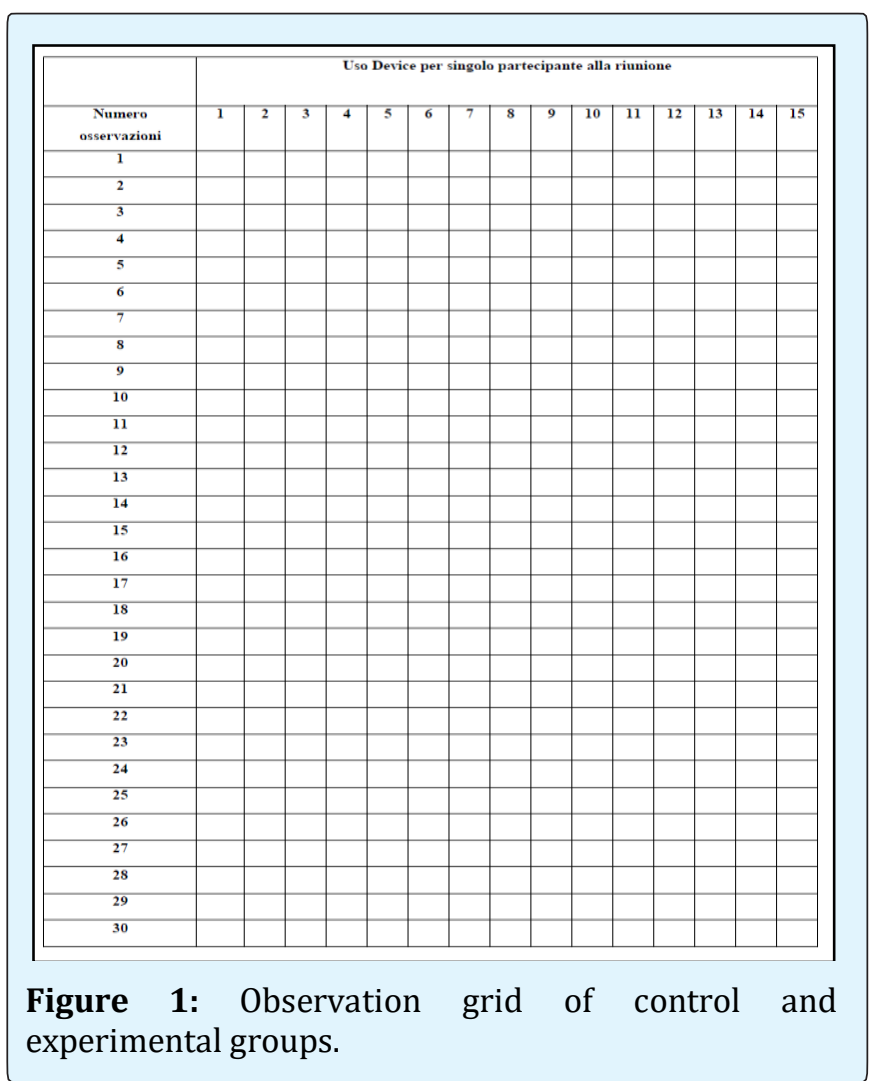




\section{Ergonomics International Journal}

The experimental phase saw the presence, inside the meeting room, on the work table, on each left side of each workstation, of an A4 sheet folded in half with the writing "put your smartphone inside me and participate in the meeting "(Figure 2).

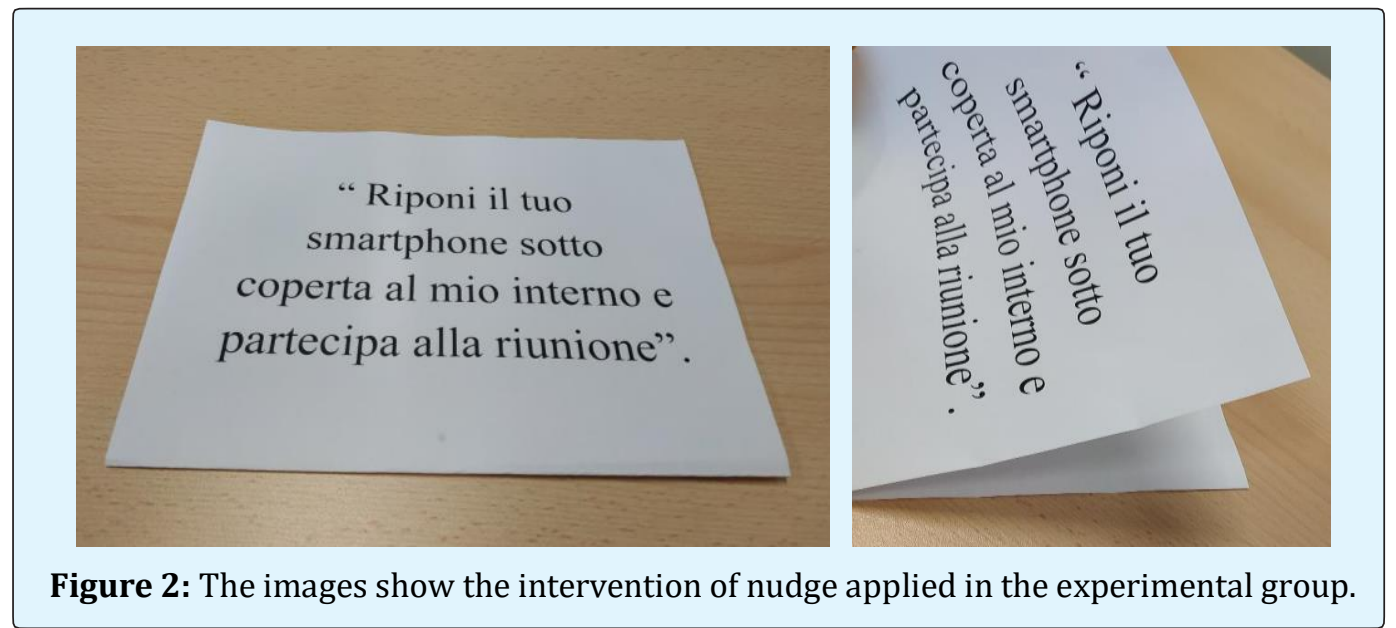

\section{Measures}

The frequency of use of the smartphone was measured by two independent observers. The observations were anchored to a list of specific behaviors that served to describe in an objective and measurable way what was intended as "interaction with the smartphone". These behaviors, reported in the table below (Table 1), had been discussed among the observers during the design phase.

\begin{tabular}{|c|c|}
\hline $\begin{array}{l}\text { Behaviors to mark as interaction with the } \\
\text { smartphone }\end{array}$ & $\begin{array}{c}\text { Behaviors to mark as not interacting with the } \\
\text { smartphone }\end{array}$ \\
\hline The subject picks up the smartphone and observes it. & The smartphone is kept next to the person on the table. \\
\hline $\begin{array}{l}\text { The subject takes the smartphone in hand to call or send } \\
\text { sms. }\end{array}$ & The device is held on the legs but is not displayed. \\
\hline $\begin{array}{l}\text { Subject touches his/her device to view notifications / } \\
\text { time etc. }\end{array}$ & $\begin{array}{l}\text { The device is taken when the person wants to go away, so } \\
\text { it is put into the bag or held in the hand. }\end{array}$ \\
\hline $\begin{array}{l}\text { The subject takes the smartphone and uses it as a tool for } \\
\text { sharing with the other members of the table (In this case } \\
\text { the frequency of the behavior to be reported will be } \\
\text { twofold: } X \text { = subject who takes the telephone in hand; X = } \\
\text { subject / s who observes / no smartphone). }\end{array}$ & $\begin{array}{l}\text { There is no good visibility of the contents of the } \\
\text { "smartphone envelope". }\end{array}$ \\
\hline $\begin{array}{l}\text { The subject takes photographs or selfies (in this case the } \\
\text { frequency of the behavior to be marked will be twofold: } \mathrm{X} \\
\text { = subject who takes the device in hand; } \mathrm{X}=\text { subject (s) } \\
\text { who observes / not the device and is part of the photo). }\end{array}$ & $\begin{array}{l}\text { There is no good visibility of the behavior of the people } \\
\text { sitting at the meeting table. }\end{array}$ \\
\hline The subject holds the smartphone without looking at it. & \\
\hline
\end{tabular}

Table 1: The table shows the specific behaviors considered and agreed upon by observers such as "interaction with the smartphone" or "non-interaction with the smartphone".

The method chosen to record people's behavior, applied in all observations, is the Momentary Time Sampling (MTS). With the MTS, the observer records whether a behavior occurs at the end of a pre-set time interval.

For both the control phase and the experimental phase, the median and mean value of people who used the cell phone during observation was calculated.

\section{Procedures}

In both phases of the research through the use of ad hoc observational grids, the total number of people who 
participated in the meeting and the number of uses of their device were recorded.

Each table was observed at a rate of $5000 \mathrm{~ms}$ (5 seconds). Each observation string included the observation of 15 people, observed in succession, for a total duration of $75000 \mathrm{~ms}$ (1.25 minutes): person $1+$ person $2[\ldots]+$ person 15 .

At the end of each observation a pause of $5000 \mathrm{~ms}$ was inserted in the audio file. The total duration of each observation string was $80000 \mathrm{~ms}$ (1.33 minutes). 300 observation grids were compiled, each of which contained n. 30 observations.

The observations were carried out by pairs of observers to evaluate the agreement between observers through the use of their own device, via which, through special earbuds, they listened to an audio file calibrated for the observation of 15 stations, which scanned every 5 seconds the station to be observed.

The order in which to consider the observation (clockwise or counterclockwise position of the stations) was agreed between the observers before the meeting.

In order not to attract attention in the meeting, one of the observers was the daughter of the owner and the other an internal consultant to the working group. The observations are made 15 days apart from each other (one on 03/26/2019 and the other on 04/09/2019).

\section{Experimental Design}

The frequency of use of smartphones was detected through an experimental design between groups with an independent variable (intervention vs non-intervention) and 2 independent groups (control vs experimental) with repeated measures on the dependent variable. The experimental phase saw the presence, inside the meeting room, on the work table, on each left side of each workstation, of an A4 sheet folded in half with the writing "put your smartphone inside me and participate in the meeting".

\section{Results}

Overall, 300 observations were made, 150 for the control group and 150 for the experimental group. The U test of Mann-Whitney was adopted to compare the ordinal variables or interval / rational variables characterized by a non-normal distribution on two independent groups.

The control group and the experimental group were considered independent, although they were formed by the same individuals, because the comparison did not take place on the individual participants, but on the level of overall use by the group. All the analyses were carried out with SPSS version 20.0 of 2009. Finally, a score p $<.050$ was considered statistically significant for all the analyses performed. The agreement between observers (IOA), or the degree to which two or more independent observers report the same observation after measuring the same event, was evaluated both in the control phase and in the experimental one. Both in the control group and in the experimental group, the agreement between observers was $100 \%$. From the values obtained we can see a statistically significant reliability of the agreement between the observers, which makes it possible to consider the data obtained as valid.

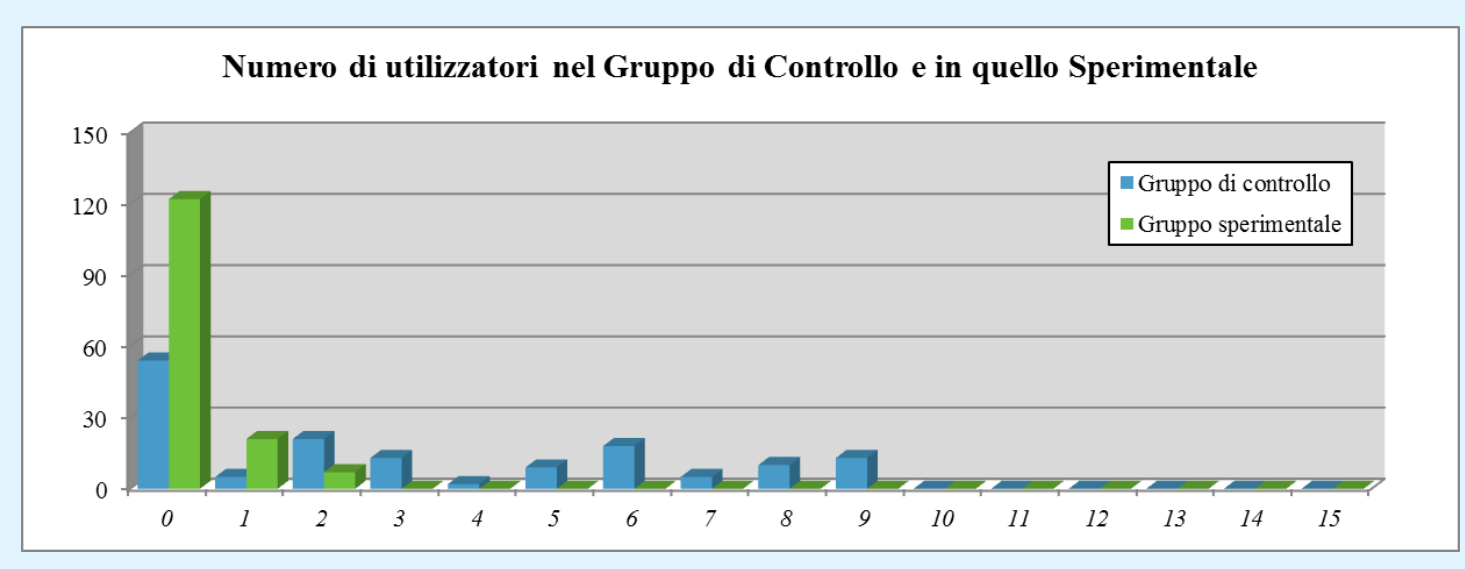

Figure 3: The graph shows the number of users, from the point of view of frequency, in the control group and in the experimental group. 


\section{Ergonomics International Journal}

In the control group: in 54 cases $(36.0 \%)$ none of the 15 participants had used the smartphone, in 5 cases (3.3\%) only one participant had used it, in 21 cases (14.0\%) 2 participants, in 13 cases (8.7\%) 3 participants, in 2 cases $(1.3 \%) 4$ participants, in 9 cases $(6.0 \%) 5$ participants, in 18 cases (12.0\%) 6 participants, in 5 cases (3.3\%) 7 participants, in 10 cases (6.7\%) 8 participants, and in 13 cases $(8.7 \%) 9$ participants. In no case did a number of 10 to 15 participants use the smartphone. In the experimental group: in 122 cases (81.3\%) none of the 15 participants had used the smartphone, in 21 cases $(14.0 \%)$ only one participant had used it, and in 7 cases (4.7\%) 2 participants. In no case did a number of 3 to 15 participants use the smartphone (Figure 3).
Regarding the use of the smartphone, significant differences were found between the control group and the experimental group ( $U=4967,000 ; p=.000)$. Specifically, the number of users during the control phase (median $=2$; interquartile distance $=6$; average $=3.19$ ) was significantly greater than that of the experimental phase ( median $=0$; interquartile distance $=0$; average $=0.23$ ). In this case, we chose to use the $U$ test given the nonnormality of the duration of the statistical units $(p=.000)$, but the averages referring to the two phases were highlighted, for a further comparison between the two conditions (Figure 4).

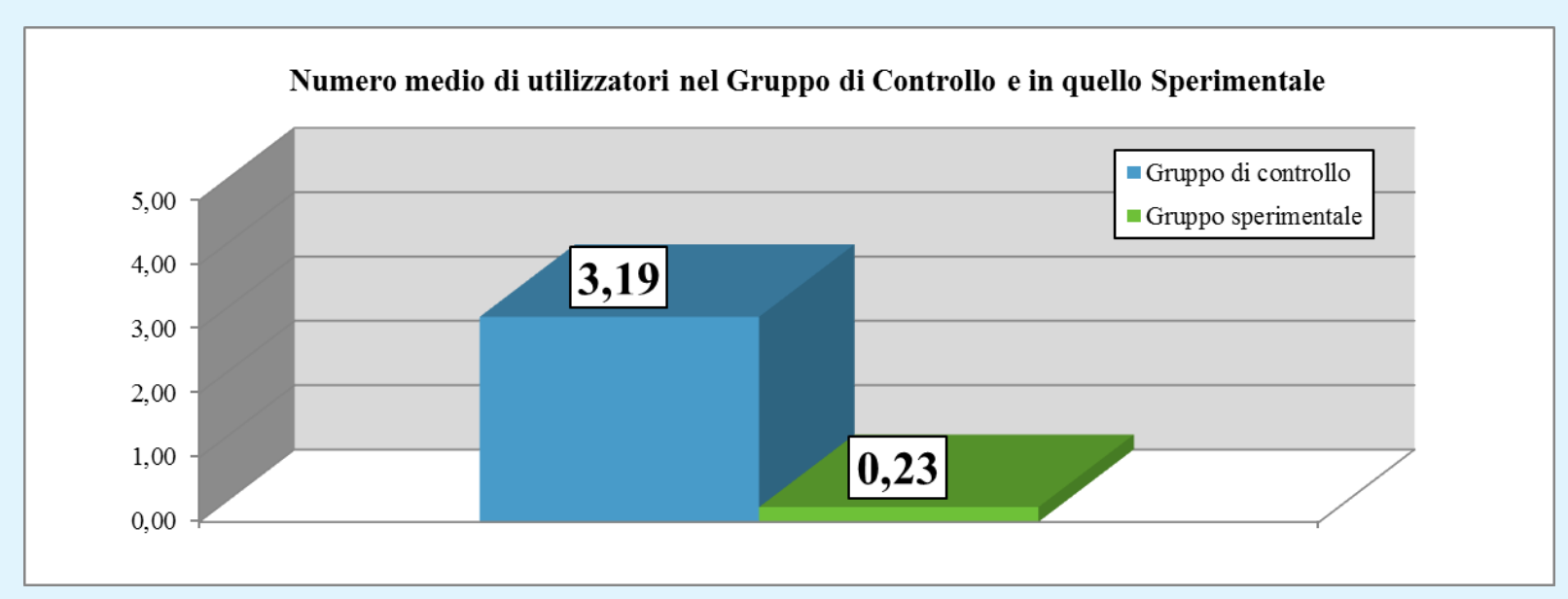

Figure 4: The graph shows the number of users, from the point of view of the average, in the control group and in the experimental group.

\section{Discussion}

The expected result was the reduction in the frequency of use of the smartphone in the presence of the independent variable. Specifically, it was expected to be lower in the experimental group (independent variable presence) than the control group (independent variable absence). The null hypothesis was that there was no difference between frequency of use in the experimental group and in the control group. The pilot study conducted by Nudge Italia highlights how small and simple Nudge interventions can help individuals and the entire community, in the immediate future and over the long-term. By reducing the frequency of use of their device in company meetings, without the use of punishments and prohibitions, could be a gentle functional push to re-establish the priorities and importance of the working groups which, on a regular weekly, fortnightly, monthly, bi-monthly, half-yearly or yearly basis, meet to discuss and share information, strategies and specific action plans. The presence of a prompt that provides clear and simple information on the behavior to be issued, together with the effectiveness of social norms, pushes the people belonging to a group to adapt more to the collective behavior [22-26].

Reducing the propensity towards multitasking allows us to be more present at an attentive level in activities such as setting and discussing the agenda, defining tasks and responsibilities, understanding and being aware of what happens in the "here and now".

\section{Ethical Approval}

All the procedures carried out comply with the ethical standards of the national research committee and the 


\section{Ergonomics International Journal}

Helsinki declaration of 1964 with its subsequent amendments.

\section{References}

1. Carr N (2011) The shallows: What the Internet is doing to our brains. WW Norton \& Company.

2. Wajcman J, Rose E (2011) Constant connectivity: Rethinking interruptions at work. Organization Studies 32(7): 941-961.

3. Lenhart A, Purcell K, Smith A, Zickuhr K (2010) Social Media \& Mobile Internet Use among Teens and Young Adults. Millennials, Pew internet \& American life project, pp: 1-51.

4. Rosen C (2008) The myth of multitasking. The New Atlantis 20: 105-110.

5. Turkle S (2011) Alone together: Why we expect more from technology and less from each other. Basic Books, New York, NY.

6. Arrington CM, Logan GD (2004) The cost of a voluntary task switch. Psychological Science 15(9): 610-615.

7. Cades DM, Werner N, Boehm-Davis DA, Trafton JG, Monk CA (2008) Dealing with interruptions can be complex, but does interruption complexity matter: a mental resources approach to quantifying disruptions. In Proceedings of the Human Factors and Ergonomics Society Annual Meeting, Thousand Oaks, CA: Sage Publications 52(4): 398-402.

8. Monsell S (2003) Task switching. Trends in Cognitive Sciences 7(3): 134-140.

9. Paoletti G (2010) Social software e Multitasking: un Virus o una Risorsa?

10. Pashler H, Johnston JC (1998) Attentional limitations in dual-task performance. In: Pashler, (Ed.), Attention. Psychology Press, Hove, UK, pp: 155-189.

11. Price C (2018) Catherine Price: How to detox from your phone. Arnoldo Mondadori Publisher.

12. Oulasvirta A, Rattenbury T, Ma L, Raita E (2012) Habits make smartphone use more pervasive. Personal and Ubiquitous Computing 16(1): 105-114.
13. Haug S, Castro RP, Kwon M, Filler A, Kowatsch T, et al. (2015) Smartphone use and smartphone addiction among young people in Switzerland. Journal of behavioural addictions 4(4): 299-307.

14. Cha SS, Seo BK (2018) Smartphone use and smartphone addiction in middle school students in Korea: Prevalence, social networking service, and game use. Health Psychology Open 5(1).

15. Thaler R, Sunstein C (2008) Nudge: Improving Decisions about Health, Wealth, and Happiness. Yale University Press, Yale.

16. Kallbekken S, Sælen H, Hermansen EAT (2013) Bridging the Energy Efficiency Gap: A Field Experiment on Lifetime Energy Costs and Household Appliances. Journal of Consumer Policy 36(1): 1-16.

17. Gerber AS, Rogers T (2009) Descriptive social norms and motivation to vote: Everybody's voting and so should you. The Journal of Politics 71(1): 178-191.

18. Goldstein NJ, Cialdini RB, Griskevicius V (2008) A Room with a Viewpoint: Using Social Norms to Motivate Environmental Conservation in Hotels. Journal of Consumer Research 35(3): 472-482.

19. Schultz PW, Nolan JM, Cialdini RB, Goldstein NJ, Griskevicius V (2007) The constructive, destructive and reconstructive power of social norms. Psychological Science 18(5): 429-434.

20. Costa DL, Kahn ME (2013) Energy conservation "nudges" and environmentalist ideology: evidence from a randomized residential electricity field experiment. Journal of the European Economic Association 11(3): 680-702.

21. Ayres I, Raseman S, Shih A (2012) Evidence from Two Large Field Experiments that Peer Comparison Feedback Can Reduce Residential Energy Usage. Journal of Law, Economics and Organization 29(5): 992-1022.

22. Festinger L (1954) A Theory of Social Comparison Processes. Human Relations 7(2): 117-140.

23. Asch SE (1951) Effects of group pressure upon the modification and distortion of judgments. In: Guetzkow H, (Eds.), Groups, Leadership and Men; Research in Human Relations, Carnegie Press, England, pp: 177-190. 


\section{Ergonomics International Journal}

24. Asch SE (1987) Social Psychology. Oxford University Press.

25. McNeil BJ, Pauker SG, Sox HC, Tversky A (1982) On the elicitation of preferences for alternative therapies. New England Journal of Medicine 306(21): 12591262.
26. Thaler RH, Benartzi S (2004) Save More Tomorrow ${ }^{\mathrm{TM}}$ : Using Behavioral Economics to Increase Employee Saving. Journal of Political Economy 112(S1): S164S187. 